\title{
Identifying factors that influence expression of eutrophication in a central California estuary
}

\author{
Brent B. Hughes ${ }^{1,2, *}$, John C. Haskins ${ }^{1}$, Kerstin Wasson ${ }^{1,2}$, Elizabeth Watson ${ }^{1,3}$ \\ ${ }^{1}$ Elkhorn Slough National Estuarine Research Reserve, Watsonville, California 95076, USA \\ ${ }^{2}$ Department of Ecology and Evolutionary Biology, University of California Santa Cruz, Santa Cruz, California 95064, USA \\ ${ }^{3}$ ORD-NHEERL, Atlantic Ecology Division, US Environmental Protection Agency, Narragansett, Rhode Island 02882, USA
}

\begin{abstract}
Coastal eutrophication models have proposed that various environmental conditions can serve as filters mediating the effects of nutrient loading on coastal ecosystems. Variation in such filters due to natural or anthropogenic causes can potentially lead to varied responses in overall eutrophication expression as well as in individual eutrophication indicators. In this study, we sought to identify factors that affect eutrophication expression at contrasting sites within one nutrient-loaded estuary in central California. We developed and applied a eutrophication expression index to 18 sites in the Elkhorn Slough estuary and then used principal components analysis of environmental drivers (nutrients) and filters to determine how they relate to overall eutrophication expression as well as to individual eutrophication indicators. We also examined the relationship between one key filter, tidal range, and eutrophication indicators. Elkhorn Slough was determined to be a moderately eutrophic estuary, with individual sites varying from being low to hypereutrophic. Eutrophication expression was explained mostly by tidal range, depth, temperature, salinity, distance to estuary mouth, and turbidity, but not by nutrient concentrations. Tidal range in particular correlated strongly with most eutrophication indicators. Sites with artificially dampened tidal range through water control structures were more eutrophic than sites with full tidal exchange. Results from this study emphasize the importance of filters in mediating the negative ecological effects of eutrophication. Coastal managers can decrease eutrophication expression at a local scale by managing for filters (e.g. increasing tidal exchange to managed wetlands), complementing efforts to reduce eutrophication at a regional scale by decreasing nutrient loading.
\end{abstract}

KEY WORDS: Eutrophication - Elkhorn Slough - Hypoxia - Environmental filters · Tidal range · Ulva $\cdot$ Chl a

\section{INTRODUCTION}

Over the last $70 \mathrm{yr}$, the addition of nitrogen to the earth's surface has doubled, mainly due to the production of industrial nitrogen for fertilizer (Vitousek et al. 1997, Gruber \& Galloway 2008, Schlesinger 2009). This has caused eutrophication via sustained delivery of anthropogenic nutrients to surface waters. Defined as an increase in the rate of organic matter additions to an ecosystem, eutrophication is one of the biggest coastal pollution problems the world faces today (Nixon 1995, Howarth et al. 2000, National Research Council 2000, Smith \& Schindler 2009). Eutrophication can lead to algal blooms, hypoxia events, decreases in biodiversity, and even dead zones, all of which can fundamentally change an ecosystem and its ecologic function (Cloern 2001, Diaz 2001, Diaz \& Rosenberg 2008).

The earliest studies of eutrophication focused on lakes, where nutrient additions often trigger direct ecological effects (Vollenweider 1976), such as increases in primary productivity and changes in 
ecosystem metabolism. Contemporary models of coastal eutrophication have been modified from the earlier freshwater models to include both direct responses or primary indicators (i.e. changes in algal growth and phytoplankton production) and indirect responses or secondary indicators (i.e. changes in dissolved oxygen and sediment biogeochemistry) with increased nutrient additions (Cloern 2001).

Coastal eutrophication models also accommodate more varied response levels by eutrophication indicators to nutrient loading. In lakes, the magnitude of the response is typically correlated with the magnitude of nutrient additions. In coastal systems, the response does not always correlate directly with the magnitude of nutrient additions. This is due to physical characteristics of the coastal environment that can mitigate or filter the effects of nutrients on primary indicators, or the effects of primary on secondary indicators (Fig. 1) (Cloern 2001). The importance of eutrophication filters can be illustrated with a comparison of eutrophication indicators in different estuaries with similar nutrient inputs. For example, San Francisco and Chesapeake Bays have similar nutrient inputs, yet productivity in San Francisco Bay is much less than that in Chesapeake Bay due to numerous differences in filters, such as residence time, depth, stratification, and tidal amplitude (Cloern 2001). The main physical filter in San Francisco Bay is a high tidal amplitude that leads to higher turbidity decreasing light availability for primary producers, whereas Chesapeake Bay has a lower tidal amplitude that leads to greater water column light penetration and higher primary productivity.

Studies identifying factors that affect eutrophication expression are rare, but vital for coastal management (McGlathery et al. 2007). Many earlier studies examining variation in drivers and filters of eutrophication either compared differences between estuar-

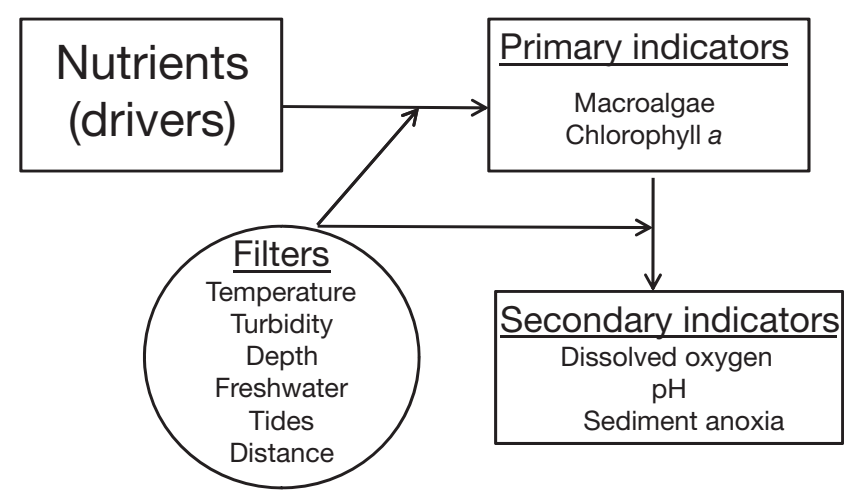

Fig. 1. Coastal eutrophication model and hypothesis. Modified from Cloern (2001) ies or used time series analysis to make inferences (e.g. Monbet 1992, Rabalais et al. 1996, Sandén \& Håkansson 1996, Harding \& Perry 1997, Allen et al. 1998, Zimmerman \& Canuel 2000, Cloern 2001); however, confounding factors such as geomorphology (for regional comparisons) and weather (for time series) decrease the rigor of these inferences about the relationship between eutrophication drivers, filters, and expression. Examining spatial variation within an estuary is perhaps the most powerful approach for identifying key filters because of fewer problems with confounding variables, and because more replication is possible. This approach has been implemented in only a few estuaries on the Atlantic coast of North America (see Boynton et al. 1996, Kemp et al. 2005), and never on the Pacific coast.

In this study, we examined the spatial variability of eutrophication expression within an estuary on the central California coast with high nutrient loads and investigated the role of filters in mediating eutrophication expression. We systematically investigated 18 sites to assess the elements of Cloern's (2001) model (Fig. 1): drivers, filters, primary and secondary indicators. We developed and implemented a eutrophication expression index (EEI) to obtain a single value for the expression of eutrophication indicators at each site, and characterized spatial patterns of this index across the entire estuarine complex encompassing the 18 sites. We used principal components analysis (PCA) to determine whether nutrients and/or filters correlated with the EEI or with individual eutrophication indicators. Finally, we examined one key filter, tidal range, in greater detail using linear regression to elucidate the relationship between tidal range and individual eutrophication indicators.

\section{MATERIALS AND METHODS}

\section{Study system}

The study location was Elkhorn Slough, which is a small California estuary located in Monterey Bay (see Fig. 2). The estuary is comprised of multiple interconnected channels, including Elkhorn Slough proper, Bennett Slough, Moro Cojo Slough, and the old Salinas River channel; however, the entire estuarine complex is generally referred to as the Elkhorn Slough estuary because the Elkhorn Slough channel is the largest and the only channel that is not obstructed at its mouth by a water control structure. The estuary is heavily influenced by surrounding agricultural practices as well as tidally driven processes leading to nu- 
trient loading on variable temporal and spatial scales. Elkhorn Slough has some of the highest levels of dissolved nutrients among US estuaries (Caffrey et al. 1997, 2002, Fry et al. 2003) (Table 1a). Long-term data suggest that nutrient levels have increased over the last $70 \mathrm{yr}$ (Caffrey 2002). Biomass of phytoplankton and macroalgae is also high (Table 1b). Some Elkhorn Slough habitats also suffer from chronic periods of nighttime hypoxia and anoxia, and daytime hyperoxia (Beck et al. 2001, Caffrey et al. 2010), along with a high occurrence of sulfate reducing bacteria, and high fluctuations in $\mathrm{pH}$ due to high productivity. The Elkhorn Slough estuary has been hydrologically altered by dikes, culverts, and tide gates (see Fig. 2), which has created artificial dampening of the tidal range upstream of water control structures. High nutrient concentrations and high primary productivity combined with high intra-estuary tidal range variation create an ideal system to test the coastal eutrophication model proposed by Cloern (2001).

Within the estuary, we selected 18 sites that are highly variable in a number of physical factors, such as distance from the mouth, tidal restriction, depth, temperature, turbidity, and freshwater influence (see Fig. 2; Tables S1 \& S2 in Supplement 1 at www. int-res.com/articles/suppl/m439p031_supp.pdf). We selected 6 sites with full tidal range ( 2.7 m maximum daily tidal range) and 12 with an artificially restricted tidal range (0.05- $1.6 \mathrm{~m}$ maximum daily tidal range).

Table 1. Summary statistics of (a) drivers (nutrient concentrations), (b) primary indicators, and (c) secondary eutrophication indicators in Elkhorn Slough during the study period of July 2008 to June 2009. Algal biomass was collected from the intertidal at only 10 sites; all the remaining values are based on averaging of data from all 18 sites (see Fig. 2). aRPD: apparent redox potential discontinuity layer. Methods for obtaining these values are described in

Supplement 1 at www.int-res.com/articles/suppl/m439p031_supp.pdf

\begin{tabular}{|c|c|c|c|c|c|}
\hline & Mean & Median & SD & Max. & Min. \\
\hline \multicolumn{6}{|l|}{ (a) Drivers } \\
\hline Nitrate $\left(\mathrm{mg} \mathrm{N}^{-1}\right)$ & 1.74 & 0.09 & 6.11 & 56.40 & 0.00 \\
\hline Ammonia $\left(\mathrm{mg} \mathrm{N}^{-1}\right)$ & 0.10 & 0.06 & 0.16 & 1.56 & 0.00 \\
\hline Phosphate (mg P $\mathrm{l}^{-1}$ ) & 0.17 & 0.05 & 0.33 & 2.35 & 0.01 \\
\hline \multicolumn{6}{|l|}{ (b) Primary indicators } \\
\hline Subtidal algal cover (\%) & 34 & 35 & 32 & 90 & 0 \\
\hline Intertidal algal cover (\%) & 36 & 33 & 31 & 90 & 0 \\
\hline Floating algal cover (\%) & 9 & 0 & 20 & 100 & 0 \\
\hline Fresh algal biomass $\left(\mathrm{g} \mathrm{m}^{-2}\right)$ & 658.4 & 148.6 & 920.0 & 2244.4 & 0.0 \\
\hline Dry algal biomass $\left(\mathrm{g} \mathrm{m}^{-2}\right)$ & 103.7 & 20.0 & 128.0 & 330.5 & 0.0 \\
\hline Chl a $\left(\mu g l^{-1}\right)$ & 12.67 & 4.41 & 26.07 & 231.89 & 0.00 \\
\hline \multicolumn{6}{|l|}{ (c) Secondary indicators } \\
\hline Time hypoxic $(\%)^{\mathrm{a}}$ & 16.4 & 6.1 & 23.2 & 73.1 & 0.0 \\
\hline Daytime dissolved $\mathrm{O}_{2}\left(\mathrm{mg} \mathrm{l}^{-1}\right)$ & 8.7 & 8.2 & 3.7 & 19.4 & 0.0 \\
\hline Daytime $\mathrm{pH}$ & 8.2 & 8.2 & 0.4 & 9.3 & 7.2 \\
\hline aRPD (cm) & 11.1 & 1.5 & 15.7 & 50.0 & 0.0 \\
\hline
\end{tabular}

\section{Data collection}

We sampled eutrophication drivers, filters, and primary and secondary indicators of eutrophication at the 18 sites in Elkhorn Slough with the goal of assessing spatial patterns of eutrophication and determining whether drivers or filters correlate with them. Data were collected at varying frequencies because some parameters, e.g. nutrients and water quality variables, were part of a 20 yr water monitoring program with a monthly sampling frequency, while others (algal cover, hypoxia, and sediment quality) were sampled only in targeted surveys for this study of eutrophication. For each site, we used a single value to characterize each driver, filter and indicator. How this single value was obtained differed by variable, and is summarized below and explained in detail in Supplement 1 at www.int-res.com/articles/suppl/ m439p031_supp.pdf, which also specifies and justifies the variables used for the various analyses.

\section{Drivers}

Dissolved inorganic nutrients enter Elkhorn Slough from several different freshwater sources that include the Salinas River and Tembladero Slough (which both flow into the Old Salinas River channel) to the south, Moro Cojo Slough to the southeast, Carneros Creek to the north, as well as runoff from adjacent land areas (Fig. 2) (Caffrey et al. 2007). Elkhorn Slough also receives water from the nutrient rich Monterey Bay, especially during periods of upwelling in late spring and early summer (Chapin et al. 2004). Water from the Old Salinas River channel contributes the greatest load of nutrients to the main channel of Elkhorn Slough; this nutrient rich water is tidally pumped up the main channel of Elkhorn Slough (Jannasch et al. 2008). Carneros Creek forms the head of the estuary and flows directly into the estuary, supplying a fraction of the nutrient input of the Old Salinas River channel.

To evaluate drivers of eutrophication, we collected surface water samples monthly at each site on ebbing tides during July 2008 to June 2009, and analyzed them for concentrations 
of nitrate as $\mathrm{N}$, ammonia as $\mathrm{N}$, and phosphate as $\mathrm{P}$. We calculated the annual mean of these monthly measurements to obtain a single measurement for each nutrient per site.

Filters

Various physical parameters that have been identified as potential eutrophication filters were measured at each site: turbidity, temperature, salinity, depth, distance to estuary mouth, and tidal range. Turbidity, temperature, and salinity measurements were taken with data sondes (YSI) during monthly collection of nutrients from July 2008 to June 2009. To obtain a single value to characterize the filter at each site, we used mean annual turbidity, the 90th percentile of temperature (because warm temperatures are important for hypoxia), and the negative of the 10th percentile of salinity (to emphasize the role of freshwater input).

We assessed the channel depth at each site during one low tide survey in May 2009, and calculated the distance of water channels from sampling sites to the estuary mouth by measuring distances on georeferenced aerial imagery in ArcGIS. To assess tidal range, a YSI sonde with a pressure transducer was deployed at each site for 2 to $4 \mathrm{wk}$ during the prime hypoxia months in the summer and early fall of July 2008 to June 2009. The sonde sampled water depth every $15 \mathrm{~min}$, and we used these measurements to calculate the maximum daily tidal range during this period.

\section{Primary indicators}

In order to assess primary indicators of eutrophication, we sampled chl $a$, and floating, subtidal, and intertidal algal mats at each site. We measured chl a concentrations at each site from July 2008 to June 2009 during the same monthly grab sampling used to assess nutrients. We used the annual mean of these monthly values to obtain a single value to characterize each site. The percent cover of floating algal mats was visually estimated monthly during the same time as water sampling, and the annual maximum of these monthly values was calculated and used to characterize each site. Subtidal and intertidal benthic algal cover was assessed once on an extreme low tide during May 2009 in order to capture one of the peak months of primary productivity in Elkhorn Slough.

\section{Secondary indicators}

We collected data on secondary indicators of eutrophication, which included hypoxia, daytime dissolved oxygen (DO) variation, hyperoxia, sediment quality, pH, and free ammonia. Hypoxia was determined in July 2008 to June 2009 during the same 2 to $4 \mathrm{wk}$ deployments of YSI data sondes as were used for assessing tidal range, with dissolved oxygen being measured every $15 \mathrm{~min}$ during this deployment. The percent of the deployment time with values of DO below the EPA's low criterion of $2.3 \mathrm{mg} \mathrm{l}^{-1}$ (US EPA 2000) was used as the single value to characterize hypoxia at each site. Daytime DO variation, hyperoxia, and $\mathrm{pH}$ data were collected at the same time as water sampling during daytime monthly sampling events (July 2008 to June 2009) using YSI data sondes. For DO variation, the annual mean of monthly values of DO variation from $100 \%$ saturation was used to characterize each site. For hyperoxia and $\mathrm{pH}$, the respective 90th percentiles of monthly DO and $\mathrm{pH}$ measurements were used. Free ammonia concentration was calculated from the same monthly grab samples used for analysis of nutrient drivers. To accurately assess average free ammonia concentration at each site, we averaged data for a longer period (from 2004-2009) because this variable displayed greater temporal variation than the other variables. Sediment quality was assessed once in the summer of 2009 by measuring depth to the apparent redox potential discontinuity (aRPD) layer. To determine the aRPD depth, a caliper was used to measure the distance between the sediment surface and the transition from brown oxic surface sediments to black reduced sediments below, with smaller values being associated with sediment anoxia or hypoxia and poor quality. This was a semiquantitative approach to determine the depth of oxygen penetration in sediments due to faunal mediated particle and porewater mixing. As the aRPD has been found to correlate well with the actual RPD depth, porewater DO, and sediment redox potential (Rosenberg et al. 2001, Diaz \& Tefry 2006), visual assessments of aRPD depth have been used as a proxy for sediment quality in benthic habitat assessments (Karlsson et al. 2010, Shumchenia \& King 2010).

\section{Statistical analysis}

Eutrophication expression index

We assessed the overall eutrophication condition of each of the 18 sites using a synthetic EEI modified 
from Bricker et al. (2003). The method uses normalization techniques to transform highly variable data into a eutrophication index, which is statistically comparable within and among estuaries. Statistical methods were modified to accommodate the known data sources and monitoring programs that exist in Elkhorn Slough. The data used and analyses conducted are described in detail in Supplements 1 \& 2 at www.int-res.com/articles/suppl/m439p031_supp. pdf.

Eutrophication values were generated for 8 eutrophication indicators (subtidal, intertidal, and floating algal cover, chl a, hypoxia, hyperoxia, aRPD, and free ammonia) based on established thresholds. Next, the values for primary indicators and secondary indicators were averaged for each site. Then the average between the primary and secondary indicators was calculated and used for an overall EEI for each site. We used these values to map the spatial extent of eutrophication status with areas being delineated by the highest high water level (Fig. 2), and further utilized these site-specific values to estimate an overall eutrophication score for the estuary. For areas behind water control structures, we assumed spatial homogeneity, and used a site-specific value for the full area of tidal restriction. For contiguous areas that experience full tidal exchange, we interpolated values between sites as a simple function of distance. To produce an estuary-wide score, we weighted eutrophication scores by both area $(A)$ and volume $(V)$ to determine any differences between area-based vs. volume based scores (Supplement 2).

\section{Principal components analyses}

To determine whether drivers or filters were related to the EEI and eutrophication indicators, we used PCA. Separate PCAs were performed for the driver, filter and indicator data, where each site was treated as a replicate. A single value per site was used for each driver, filter, and indicator, as described above. We used 3 drivers (nitrate, phosphate, ammonia), 6 filters (temperature, turbidity, depth, salinity, tidal range, and distance to mouth), 3 primary indicators ( $\mathrm{chl} a$, subtidal algal cover, and floating algal cover), and 3 secondary indicators (DO variation, aRPD, and $\mathrm{pH}$ ). Each variable was tested for skewness and homogeneity of variance and log transformation was used if one of the assumptions was violated (Underwood 1997). The PCA was run using SPSS statistical software (v. 17) by developing a correlation matrix using a varimax rotation method.
Principal components (PC) with eigenvalues $<0.9$ were discarded because they did not explain more than the original variables (Clarke \& Warwick 2001). Variables associated with each component with an absolute correlation (PC weights) value $<0.40$ were also discarded. This was a conservative PC weight based on previous reported values (Graham 2003, Hughes 2010) and reduced the complexity of interpreting an excessive number of variables.

The scores for the first 2 PCs for each site were plotted and coded by their EEI to visualize the influence of drivers and filters on eutrophication expression. PC weights were used to label each axis to help characterize the filters and drivers of eutrophication.

\section{Determination of key eutrophication drivers and filters}

In addition to the above analyses identifying key correlates of the EEI, we conducted additional analyses to determine which potential drivers and filters had the strongest relationship with eutrophication indicators. To do this, we used principal component regression (PCR) because it provides a robust analysis when there is a high degree of multicollinearity, such as in the driver and filter variables (Graham 2003). The principal component scores were the predictor variable used to examine the combined relationships of significant variables of the principal component and the response variable (eutrophication indicators). The same PC scores of the driver and filter variables described above were used for the PCR. However, if a predictor variable (i.e. drivers or filters) had an absolute correlation value $>0.4$ for one or more PCs, then it was removed from the analysis to avoid complications of interpreting PC modes, and was used as a stand-alone variable in the multiple regression. PCA was again run without the standalone variable. A PCA was run on eutrophication indicators to help identify the importance of filters and drivers of eutrophication, using a similar data set as that for the EEI, with some modifications to avoid multicollinearity of certain variables (see Supplement 1).

After we determined the treatment of the various $\mathrm{PCs}$, we ran the PC regression using a stepwise multiple regression to determine the key predictor PCs of eutrophication using SPSS statistical software (v. 17). A multiple regression was run using the driver and filter PCs as the predictor against each significant indicator PC. Running correlation analysis of predictor PCs (drivers and filters) against indicator PCs 
enabled identification of key drivers, filters, and indicators of eutrophication in Elkhorn Slough. Partial correlation coefficients (PCC) were used to determine positive or negative relationships while holding other variables constant. All alpha levels were set at 0.05 .

Linear regressions of tidal range vs. eutrophication indicators

One of the key filters apparent from the spatial analysis and from the PC analysis was tidal range, which is artificially restricted at many of the study sites. To more closely examine the specific relationship between tidal range and eutrophication indicators, we conducted simple linear regressions between tidal range and 6 eutrophication indicators (chl $a$, subtidal algal cover, floating algal cover, DO variation, aRPD, and $\mathrm{pH}$ ). A Bonferroni correction was applied to avoid Type I errors by taking the original alpha and dividing it by the number of independent tests to generate a more conservative alpha.

To better understand the relationship between DO variation (measured in our monthly water quality sampling) and hypoxia, we also conducted a linear regression between DO variation and percent time each site went hypoxic. This helped us to determine if DO variation was a useful indicator of hypoxia. The relationship between tidal range and hypoxia was graphed to examine the relationship between these variables that are of high coastal management interest.

\section{RESULTS}

\section{Eutrophication expression: estuary-wide mean and spatial variation between sites}

\section{Eutrophication expression index}

Eutrophication indices varied spatially across the 18 sites, from low to hypereutrophic (Fig. 2, Tables S2 \& S4). The main channel of Elkhorn Slough was moderately eutrophic near the mouth and middle, and increased to highly eutrophic near the head. The overall spatially averaged EEI value for the Elkhorn Slough estuarine complex was 0.539 and 0.450 for area-based and volume-based assessments, respectively, making it a moderately eutrophic estuary (Table S3c).

\section{Drivers}

Nutrient concentrations in Elkhorn Slough were very high compared to reported eutrophication thresholds (Table 1a). Mean nitrate and phosphate exceeded high thresholds, and mean ammonia reached moderate to high thresholds based on values reported by Caffrey et al. (1997), Caffrey (2002), and Bricker et al. (2003). However, nutrient concentrations were highly variable among sites (Table S2); $33 \%$ of the sites had means exceeding the high nitrogen threshold $\left(>1.0 \mathrm{mg} \mathrm{N}^{-1}\right.$ ), and $39 \%$ had means that exceeded the high phosphorous threshold $(>0.1 \mathrm{mg} \mathrm{P}$ $\mathrm{l}^{-1}$ ) established by Bricker et al. (2003). Nutrients were highest at sites that were closest to freshwater inputs (i.e. Old Salinas River channel and Carneros Creek) (Table S2), and were at times 50 and $20 \times$ greater than the high threshold proposed by Bricker et al. (2003) for nitrogen and phosphorous, respectively.

\section{Primary indicators}

Mean algal cover, biomass, and chl $a$ in all sites in Elkhorn Slough were moderate (Table 1b); however, at least one primary indicator was high at all sites (Table S2). Although there was high cover of algae at many sites, only a few species of green macroalgae comprised the algal assemblages in Elkhorn Slough.

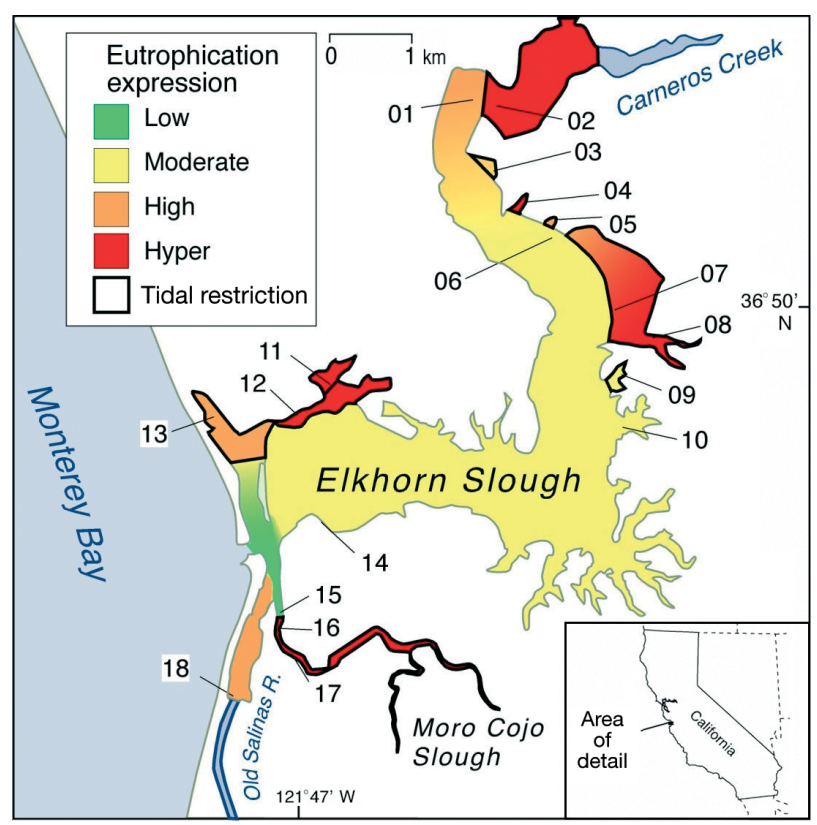

Fig. 2. Monitoring stations in Elkhorn Slough with spatially interpolated eutrophication indices. See Table S1 in Supplement 1 at www.int-res.com/articles/suppl/m439p031_ supp.pdf for site descriptions 
Table 2. Principal component weights for eutrophication (a) drivers, (b) filters and (c) indicators. Percent variance explained among variables are in parentheses. aRPD: apparent redox potential discontinuity layer; DO: dissolved oxygen. Significant weights $>0.40$ are highlighted in bold

\begin{tabular}{|c|c|c|}
\hline & \multicolumn{2}{|c|}{ Principal component } \\
\hline (a) Drivers & $1(63.5 \%)$ & $2(30.0 \%)$ \\
\hline Nitrate $^{a}$ & 0.863 & 0.389 \\
\hline Ammonia $^{a}$ & 0.962 & -0.032 \\
\hline Phosphate $^{a}$ & 0.114 & 0.984 \\
\hline (b) Filters & $1(43.1 \%)$ [41.9\%] & $2(28.1 \%)[33.6 \%]$ \\
\hline Tidal range ${ }^{b}$ & -0.532 & -0.548 \\
\hline Subtidal depth ${ }^{\mathrm{a}}$ & $-0.691[-0.714]$ & $-0.333[-0.326]$ \\
\hline Temperature & $0.227[0.252]$ & $0.936[0.926]$ \\
\hline Freshwater & $0.853[0.860]$ & $0.009[-0.008]$ \\
\hline Turbidity & 0.769 [0.795] & $-0.148[-0.137]$ \\
\hline Distance to mouth & $-0.246[-0.184]$ & $0.853[0.901]$ \\
\hline (c) Indicators & $1(49.6 \%)$ & $2(25.4 \%)$ \\
\hline $\mathrm{Chl} a^{\mathrm{a}}$ & 0.354 & 0.845 \\
\hline Floating algal cover & 0.733 & 0.000 \\
\hline Subtidal algal cover & 0.250 & -0.863 \\
\hline Daytime $\mathrm{pH}$ & 0.740 & 0.584 \\
\hline $\mathrm{aRPD}$ & -0.941 & -0.016 \\
\hline Daytime DO varianc & 0.732 & 0.062 \\
\hline \multicolumn{3}{|c|}{$\begin{array}{l}\text { a Variable log transformed prior to analysis } \\
{ }^{\mathrm{b}} \text { Removed as stand-alone variable for multiple regres- } \\
\text { sion; data in square brackets are the PC weights after } \\
\text { tidal range was removed }\end{array}$} \\
\hline
\end{tabular}

Floating algal mats were dominated primarily by Ulva intestinalis, but also included Rhizoclonium riparium and Chaetomorpha sp. Subtidal zones were dominated by U. lactuca, U. expansa, and U. lobata. The intertidal zone was dominated by U. lactuca, $U$. intestinalis, $R$. riparium, Chaetomorpha sp., and Gracilariopsis andersonii.

\section{Secondary indicators}

There was also significant expression of secondary indicators of eutrophication in the estuary (Table 1c). This includes periods of hypoxia, anoxia, high $\mathrm{pH}$, and anoxic sediments. There was also high variability in hypoxia, daytime DO, pH, and sediment quality among sites (Table S2).

\section{Correlation between EEI and indicators}

Nutrient levels were not strongly correlated with the EEI of the sites; the plot of PC1 vs. PC2 Drivers displayed no separation in eutrophication expression among the sites despite their great variation in nutrient concentrations (Fig. 3a, Table 2a). While the PC analysis did not show clustering of sites characterized by nutrients alone into the eutrophication categories, it is noteworthy that hypereutrophic sites were never found near the origin of the axes, suggesting some role of nutrients at sites with a hypereutrophic status.

Eutrophication filters were strongly correlated with the EEI. The plot of PC1 vs. PC2 Filters shows clear separation of sites by their EEI (Fig. 3b). All 6 filters had significant PC weights in the PCA analysis (Table 2b), so these filters all appear to contribute to variation in eutrophication patterns (Fig. 3b, Table 2b). Sites with greater tidal range, depth, salinity, and lower turbidity (PC1) generally had lower eutrophication expressions, whereas sites with greater freshwater inputs, turbidity, and lower depths and tidal ranges had higher eutrophication expressions. This gradient among the sites segregates marine from estuarine sites. The PC2 axis indicated that sites with lower eutrophication had lower temperatures and were closer to the mouth of the
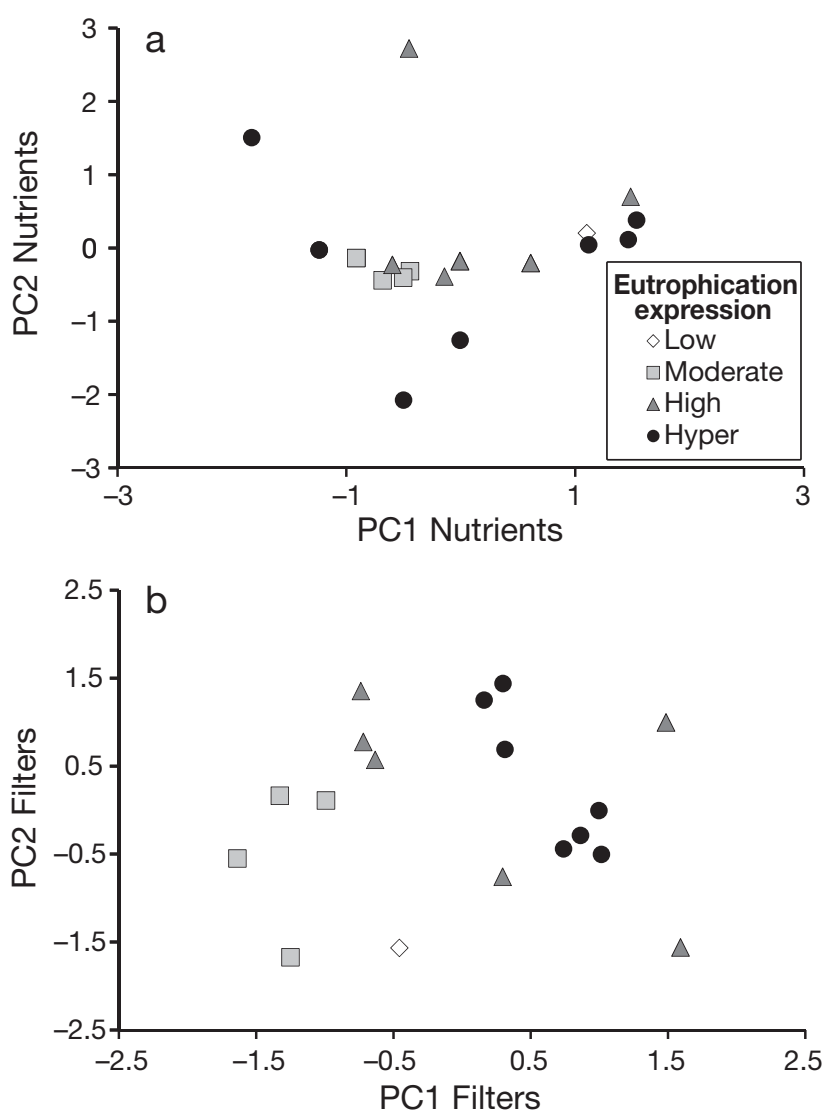

Fig. 3. Principal components analysis (PCA) of (a) nutrients and (b) filters. Points represent PC scores for each site $(\mathrm{N}=$ 18), with eutrophication expression index being indicated by markers. See Table 2a,b for description of significant PC weights 
estuary, and sites further from the mouth with higher temperatures had higher eutrophication indices.

Eutrophication filters were also correlated with the eutrophication indicators. To run the analysis, we first removed tidal range from the PC Filters as a stand-alone variable because it loaded significantly on both axes (Table 2b). Next, we ran a multiple regression with tidal range as the dependent variable and PC1 and PC2 as the independent variables to ensure that there was no collinearity between the PCs and tidal range $\left(F_{1,17}=2.951, \mathrm{R}^{2}=0.156, \mathrm{p}=\right.$ $0.105)$. We ran the multiple regression with PC1 and PC2 Filters, tidal range as a stand-alone variable, PC1 Drivers (nitrate and ammonia) and phosphate as a stand-alone variable, since phosphate was the only variable with a significant weight for PC2 (Table 2a). The multiple regression resulted in a significant negative relationship of PC1 Indicators with tidal range (Fig. 4) and a significant positive relationship of PC2

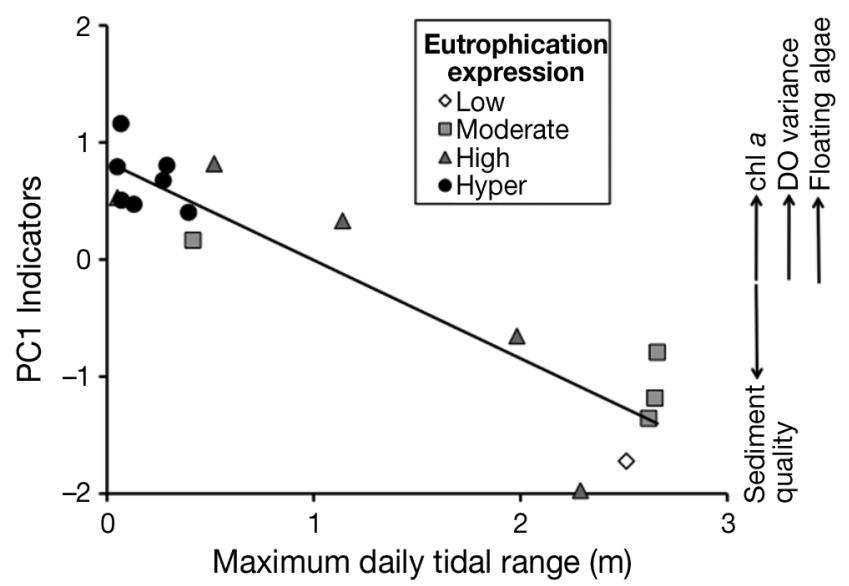

Fig. 4. Multiple regression analysis of principal component (PC) scores for tidal range vs. PC1. Variables with significant $\mathrm{PC}$ weights are indicated on each axis. Variables included in the stepwise regression were PC1 Drivers, phosphate, PC1 Filters, PC2 Filters, and tidal range (see Table 3 for statistical results)

Table 3. Stepwise multiple regression of eutrophication indicators versus principal components $(\mathrm{PCs})$ of eutrophication drivers and filters $(\mathrm{N}=18)$. PCC: partial correlation coefficients, used to determine relationships while holding other variables constant. The independent variables were PC1 Drivers, phosphate, PC1 Filters, PC2 Filters, and tidal range

\begin{tabular}{|lcccccr|}
\hline & Entered variables & df & $\mathrm{R}^{2}$ & $F$ & $\mathrm{p}$ & PCC \\
\hline PC1 indicators & & & & & & \\
Step 1 & Tidal range & 1 & 0.768 & 52.923 & $<0.0005$ & -0.876 \\
Step 2 & PC2 filters & 2 & 0.823 & 34.804 & $<0.0005$ & 0.234 \\
PC2 indicators & & & & & & \\
Step 1 & PC1 filters & 1 & 0.417 & 11.458 & 0.004 & 0.646 \\
\hline
\end{tabular}

Filters with PC1 Indicators (Table 3). Tidal range correlated positively with aRPD and negatively with floating algal cover, daytime DO variance, and daytime $\mathrm{pH}$. In contrast, $\mathrm{PC} 2$ Filters (temperature and distance to mouth) were negatively correlated with aRPD and positively correlated with floating algal cover, daytime DO variance, and daytime $\mathrm{pH}$. Lastly, PC2 Indicators had a significant positive correlation with PC1 Filters (Table 3). More specifically, higher freshwater inputs and turbidity were correlated with greater chl a concentrations and daytime $\mathrm{pH}$, whereas greater subtidal depth was positively correlated with greater subtidal algal cover (Table $2 b, c)$.

Nutrients were never entered into the stepwise multiple regression models as significant explanatory variables along with filter variables, indicating that filters explained the most variation in eutrophication. However, nutrients had a weak significant relationship with eutrophication indicators when analyzed without filter variables. The PC2 Indicators had a significant negative relationship with phosphate $\left(F_{1,17}=4.689, \mathrm{R}^{2}=0.227, \mathrm{p}=0.046, \mathrm{PCC}=\right.$ 0.476). Sites with high phosphate were associated with high chl a concentrations and $\mathrm{pH}$, but low subtidal algal cover (Table 2a,c).

\section{Relationship between tidal range and eutrophication indicators}

Tidal range had the most significant correlation with the eutrophication indicators (Figs. 2 \& 3, Table 3), indicating that it is the strongest contributor to the separation of sites by filters. Therefore, a reduced model (simple linear regression) was used to more closely examine pairwise relationships between tidal range and individual indicators. Tidal range was correlated with all of the eutrophication indicators except for subtidal algal cover (Table 4). Tidal range was negatively correlated with $\mathrm{chl} a_{\text {, }}$ floating algal cover, daytime $\mathrm{pH}$, and daytime DO variation; and was positively correlated with aRPD.

Since hypoxia is a primary concern for overall ecosystem health, we investigated the relationship between DO variation (used in the previous analyses) and percent time hypoxic at sites where DO was measured continuously (every $15 \mathrm{~min}$ ) during 2008-09. There was a significant relationship between DO variation and percent time hypoxic (Fig. 5a). 
Table 4. Simple linear regression analysis of individual eutrophication indicators (chl $a$, floating algal cover, subtidal algal cover, daytime $\mathrm{pH}$, apparent redox potential discontinuity [aRPD], and daytime dissolved oxygen [DO] variance) vs. tidal range. All alphas were set at 0.05 , while conservative measurements of alpha were set at 0.01 using a Bonferroni correction. * Significant relationship ( $\alpha=0.05)$. ${ }^{* *}$ Highly significant Bonferroni correction $(\alpha=0.01)$

\begin{tabular}{|lccccccc|}
\hline $\begin{array}{l}\text { Predictor } \\
\text { variable }\end{array}$ & $\begin{array}{c}\text { Response } \\
\text { variable }\end{array}$ & df & $\mathrm{R}^{2}$ & $F$ & $B$ & $\mathrm{p}$ \\
\hline Tidal range & $\begin{array}{c}\text { chl } a^{\mathrm{a}} \\
\end{array}$ & 1 & 0.292 & 6.584 & -0.459 & $0.021^{*}$ \\
& $\begin{array}{l}\text { Floating algal cover } \\
\text { Subtidal algal cover }\end{array}$ & 1 & 0.445 & 12.838 & -23.555 & $0.002^{* *}$ \\
& Daytime pH & 1 & 0.470 & 14.212 & -0.197 & $0.002^{* *}$ \\
& DO variation & 1 & 0.269 & 5.882 & -8.793 & $0.027^{*}$ \\
aRPD & 1 & 0.714 & 39.853 & 11.571 & $<0.0005^{* *}$ \\
a Variable log transformed prior to analysis & & & \\
\hline
\end{tabular}

results from this study within a relatively small estuary with high variation among sites show that a single score is probably not very useful at a local scale. Also, managers should be cautious in using spatial analysis to determine overall eutrophication expression because volume-based estimates can yield a different expression than area-based estimates. In the case of Elkhorn Slough, the areabased score was higher than the volume-based score because many of the restricted areas had low volume, yet had extensive intertidal area.
Next, we examined the relationship between tidal range and percent time hypoxic at all of our sites, which resulted in a significant negative relationship (Fig. 5b). The role of tidal range was also readily visualized by examining the geographic patterns of expression of eutrophication and tidal restriction (Fig. 2). In particular, all hypereutrophic areas were those that were behind water control structures.

\section{DISCUSSION}

\section{Importance of scale in determining eutrophication expression}

Overall, the estuarine wetlands of Elkhorn Slough exhibit levels of eutrophication equal to or exceeding those of other estuaries that are considered eutrophic in the United States, e.g. San Francisco Bay, Newport Bay, Chesapeake Bay, and Tampa Bay (Scavia \& Bricker 2006). Elkhorn Slough wetlands exceed thresholds for nutrient concentrations, algal cover and biomass, chl $a$, hypoxia and anoxia, sediment quality, and free ammonia production. The overall eutrophication score for the entire estuary, based on spatial averaging, was moderate. However, eutrophication expression within the estuary was highly variable (low to hypereutrophic). For instance, some sites are hypoxic a large percentage of time while others never become hypoxic. Eutrophication assessments at the single estuary scale could be improved by capturing both spatial and temporal scales of variation in eutrophication indicators, providing a range of observed values as well as averages. Although estuary-scale scores are useful for large-scale geographic characterizations,

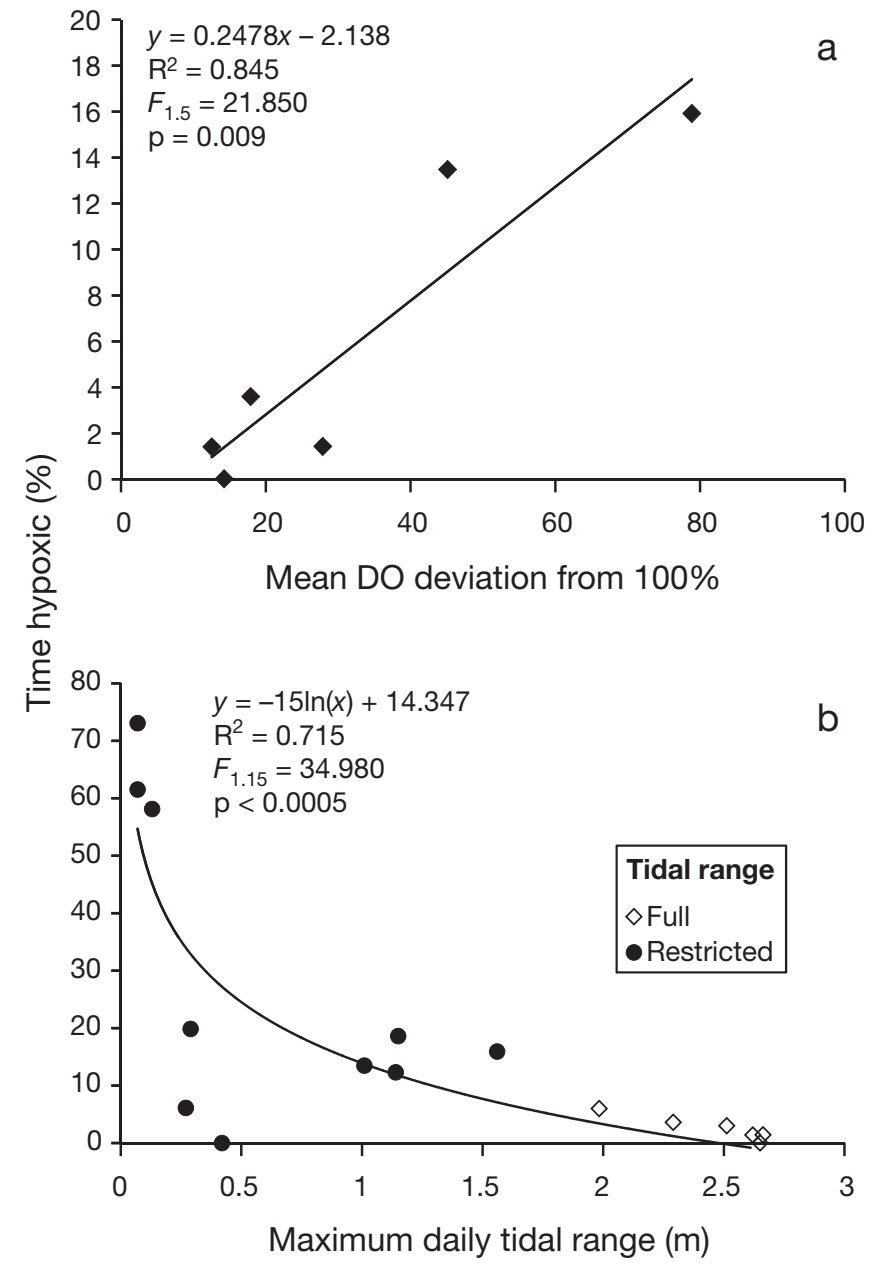

Fig. 5. Linear regression showing the relationship between (a) hypoxia vs. DO deviation, and (b) percent time hypoxic vs. tidal range. Tidal range was measured during 2 to 4 wk deployments and does not necessarily reflect the maximum tidal range for the year, which is similar for all fully tidal sites. Sites in (b) were labeled according to tidal range category: full (no water control structure, $\diamond$ ) or restricted (behind water control structure, 


\section{Importance of filters in mediating eutrophication expression}

The dramatic variation in eutrophication expression between sites enabled us to conduct powerful analyses that examined key correlates of eutrophication expression, and could be a useful approach for other estuaries. Taken together, the filters we measured explained site variation in eutrophication expression, as summarized by the strong correlation (Table 3) between filters and eutrophication indicators. The powerful analytical approach allowed us to examine groupings of co-varying drivers, filters, and indicators, as well as individual ones that were dominant, and to examine complex collinearity. Physicochemical filters explained much of the variation in overall eutrophication expression among sites, as well as variations in levels of individual indicators among sites. Also, different filters were important for different indicators; tidal range explained variation in patterns of floating algal mats, DO deviation, hypoxia, $\mathrm{pH}$, aRPD, and chl $a_{i}$ temperature and distance to mouth explained variation in floating algal mats, DO deviation, $\mathrm{pH}$, and aRPD; and depth, freshwater, and turbidity explained variation in $\mathrm{pH}$, subtidal algal cover, and chl a. Other studies have tested filters of eutrophication (Monbet 1992, Boynton et al. 1996, Kemp et al. 2005), but our study is the first powerful test within a single estuarine system of the model proposed by Cloern (2001), and our results strongly support this model.

Filters not only explained variation in eutrophication expression, but actually did so better than did drivers. Sites with the highest nutrient concentrations were not the ones with the highest eutrophication scores, or with significant positive correlations with individual indicators such as algal cover or hypoxia. Of all the eutrophication indicators, only chl $a$ and daytime $\mathrm{pH}$ had a significant positive relationship with nutrients (phosphate), but this is probably a weak correlation because only $25 \%$ of the variation in the PC2 Indicators axis was explained by its variables (chl a, subtidal algae, and aRPD) (Table 2c). It should be noted that nutrient loads at each site were not measured and could have shown a correlation with eutrophication expression, but we consider this unlikely based on our knowledge of these sites. This finding contrasts with the results of studies in other estuaries where nutrient concentrations have been shown to correlate well with eutrophication symptoms, e.g. Maryland coastal bays (Boynton et al. 1996) and Chesapeake Bay (Kemp et al. 2005). It is possible that such correlations only occur over lower ranges in nutrient concentrations; Elkhorn Slough has much higher nutrient concentrations than these other estuaries, with a mean nitrogen concentration of $1.7 \mathrm{mg} \mathrm{l}^{-1}$ and a maximum of $56.4 \mathrm{mg} \mathrm{l}^{-1}$. In very nutrient-loaded systems, nutrient concentrations may not be as good predictors of eutrophication as are various filters.

\section{Tidal range as a key filter of eutrophication expression}

Tidal range has been identified in other studies as an important variable affecting estuarine eutrophication (Monbet 1992, Cloern 2001, Martinetto et al. 2010), and our results from Elkhorn Slough found tidal range to be the single most important filter of eutrophication expression, both in the multivariate and univariate analyses. Decreases in tidal range correlated significantly with increased DO variation, increased chl $a$, increased daytime $\mathrm{pH}$, decreased sediment quality, and increased cover of floating algal mats. In our study, variation in tidal range was the result of artificial water control structures, but the results are also relevant to natural variation in tidal range (i.e. differences between micro- and macrotidal estuaries). Other studies of natural variation in tidal range between estuaries (Young et al. 1997, Edgar et al. 2000) revealed significant water quality and biological community differences attributed to tidal range.

There are numerous mechanisms by which tidal range may affect eutrophication expression at Elkhorn Slough and other estuaries. A filter such as tidal range can affect both how nutrients stimulate primary production or how such production can lead to secondary indicators of eutrophication; our modification of Cloern's conceptual model indicates both of these potential roles for filters (Fig. 1). Greater tidal amplitude increases tidal mixing, which leads to decreases in stratification and residence time, and increases the transport of primary producers and nutrients out of the system (Nixon et al. 1996, Cloern 2001, Uncles et al. 2002). Martinetto et al. (2010) found that increases in tidal range can filter the effects of eutrophication on secondary indicators (hypoxia and benthic invertebrate abundance); despite high nutrient inputs and algal growth, secondary indicators of eutrophication were absent in areas of high tidal exchange. Increases in residence time can lead to higher temperatures and phytoplankton blooms (Largier et al. 1997, Valiela et al. 1997). Temperature directly affects the photosynthetic and respiration rates of algae, especially in opportunistic species like 
Ulva lactuca and U. linza (Kanwisher 1966, Lüning 1990). The increase in metabolic activity may lead to greater fluctuations in secondary indicators, such as $\mathrm{pH}$ and DO, as noted in this study at sites with lower tidal ranges and higher temperatures.

Coastal managers can influence tidal range in wetlands behind water control structures. Most water control structures at Elkhorn Slough and other estuaries around the world were constructed to allow farming in floodplains and prevent inundation of farmed fields with salt water (Caffrey \& Broenkow 2002, Williams \& Orr 2002). For Elkhorn Slough, there are 2 aspects of agricultural development that have negative consequences for the estuarine ecosystem: nutrient run-off and artificial tidal dampening; these work in concert to influence eutrophication expression. The most eutrophic sites are the ones behind water control structures. Negative ecological effects of water control structures, both direct and indirect, include loss of diversity or decreases in abundances of ecologically important species (Sanzone \& McElroy 1998, Ritter et al. 2008). However, the results from this study indicate that even moderate increases in tidal exchange through water control structures can mediate the worst eutrophication problems, and thus potentially enhance biological communities. For example, increasing the tidal range of most restricted sites in Elkhorn Slough to $\sim 1 \mathrm{~m}$ could dramatically reduce hypoxia (Fig. 5b). Although increases in tidal range offer managers potential for more local control, reductions of nutrient inputs at the watershed scale must be the ultimate solution to eutrophication problems in the long run.

\section{Filter analyses to examine variation within estuaries: future studies}

This study used a rigorous approach to identify filters mediating eutrophic expression. The success of this approach came from using 18 different sites within an estuary, which gave us statistical power to investigate correlations between eutrophication and filters. This approach is readily transferrable to other systems, if a design using multiple sites is implemented, with measurement of primary and secondary indicators and factors that may serve as potential filters. The multivariate approach could also be applied to larger scales (e.g. regional, national, and global), or could be used to examine even finer scales within single estuaries.

There is great value for researchers to monitor filters and indicators (not just nutrients) for characteriz- ing and predicting eutrophic conditions in coastal environments. This approach does not necessarily require a large investment of resources. In this study, we were able to use a combination of monthly sampling, one-time rapid assessment surveys, and $2 \mathrm{wk}$ hypoxia deployments to obtain very robust statistical relationships. This type of effort is within the capabilities of many coastal monitoring organizations and highlights the importance of spatial coverage across varying sites. Physico-chemical features were emphasized, using easily measurable parameters such as depth, salinity, and temperature. Although this study did not examine the actual mechanisms by which these parameters may affect eutrophication (i.e. underlying biogeochemical processes), it identified key parameters that correlate with eutrophication expression. These parameters have value in informing management strategies because managers can regulate freshwater or tidal inputs that affect flushing, whereas they do not directly manage biogeochemical processes.

Acknowledgements. We thank E. Van Dyke for spatial analyses; K. Coale and N. Welschmeyer for use of facilities; $\mathrm{S}$. Tanner for nutrient analysis at Moss Landing Marine Labs; S. Bricker and J. Ferreira for advice on generating the EEI; R. Eby, S. Shaw, J. Hatfield, R. Priesler, and P. Brown for volunteer field support; K. Johnson and J. Plant at the MBARI LOBO program for additional data; W. M. Kemp, R. Preisler, P. Raimondi, and 4 anonymous reviewers for extensive suggestions that greatly strengthened the manuscript and improved Fig. 1; and K. Thomasberg and the Monterey County Water Resources Agency (MCWRA) for long-term financial support for nutrient analyses. This work was funded as part of a PG\&E special projects non-point source pollution grant with the Elkhorn Slough Foundation, Central Coast Regional Water Quality Control Board, California Environmental Protection Agency and the Monterey Community Foundation (Grant \# 20060387). This study was also supported by a grant from the Estuarine Reserve division of the NOAA.

\section{LITERATURE CITED}

Allen JR, Slinn DJ, Shammon TM, Hartnoll RG, Hawkins SJ (1998) Evidence for eutrophication of the Irish Sea over four decades. Limnol Oceanogr 43:1970-1974

Beck NG, Fisher AT, Bruland KW (2001) Modeling water, heat, and oxygen budgets in a tidally dominated estuarine pond. Mar Ecol Prog Ser 217:43-58

> Boynton WR, Hagy JD, Murray L, Stokes C, Kemp WM (1996) A comparative analysis of eutrophication patterns in a temperate coastal lagoon. Estuaries 19:408-421

Bricker SB, Ferreira JG, Simas T (2003) An integrated methodology for assessment of estuarine trophic status. Ecol Model 169:39-60

Caffrey J (2002) Biogeochemical cycling. In: Caffrey JM, Brown M, Tyler WB, Silberstein M (eds) Changes in a 
California estuary: a profile of Elkhorn Slough. Elkhorn Slough Foundation, Moss Landing, CA, p 215-236

Caffrey J, Broenkow W (2002) Hydrography. In: Caffrey JM, Brown M, Tyler WB, Silberstein M (eds) Changes in a California estuary: a profile of Elkhorn Slough. Elkhorn Slough Foundation, Moss Landing, CA, p 29-42

Caffrey J, Shaw S, Silberstein M, De Vogelaere A, White M (1997) Water quality monitoring in Elkhorn Slough: a summary of results 1988-1996. Elkhorn Slough Technical Report Series 1997:1

Caffrey JM, Harrington N, Ward B (2002) Biogeochemical processes in a small California estuary. 1. Benthic fluxes and pore water constituents reflect high nutrient freshwater inputs. Mar Ecol Prog Ser 233:39-53

> Caffrey JM, Hollibaugh JT, Bano N, Haskins J (2010) Effects of upwelling on short-term variability in microbial and biogeochemical processes in estuarine sediments from Elkhorn Slough, California, USA. Aquat Microb Ecol 58: 261-271

> Chapin TP, Caffrey JM, Jannasch HW, Coletti LJ, Haskins JC, Johnson KS (2004) Nitrate sources and sinks in Elkhorn Slough, California: results from long-term continuous in situ nitrate analyzers. Estuaries 27:882-894

Clarke KR, Warwick RM (2001) Changes in marine communities: an approach to statistical analysis and interpretation. Plymouth Marine Laboratory, Plymouth

> Cloern JE (2001) Our evolving conceptual model of the coastal eutrophication problem. Mar Ecol Prog Ser 210: 223-253

> Diaz RJ (2001) Overview of hypoxia around the world. J Environ Qual 30:275-281

> Diaz RJ, Rosenberg R (2008) Spreading dead zones and consequences for marine ecosystems. Science 321: 926-929

> Diaz RJ, Tefry J (2006) Comparison of sediment profile image data with profiles of oxygen and Eh from sediment cores. J Mar Syst 62:164-172

Edgar GJ, Barrett NS, Graddon DJ, Last PR (2000) The conservation significance of estuaries: a classification of Tasmanian estuaries using ecological, physical and demographic attributes as a case study. Biol Conserv 92: 383-397

$>$ Fry BF, Grace A, McClelland JW (2003) Chemical indicators of anthropogenic nitrogen loading in four Pacific estuaries. Pac Sci 57:77-101

> Graham MH (2003) Confronting multicollinearity in ecological multiple regression. Ecology 84:2809-2815

> Gruber N, Galloway JN (2008) An Earth-system perspective of the global nitrogen cycle. Nature 451:293-296

> Harding LW Jr, Perry ES (1997) Long-term increase of phytoplankton biomass in Chesapeake Bay, 1950-1994. Mar Ecol Prog Ser 157:39-52

Howarth R, Anderson D, Cloern J, Elfring C and others (2000) Nutrient pollution of coastal rivers, bays, and seas. Issues Ecol 7:1-15

- Hughes BB (2010) Variable effects of a kelp foundation species on rocky intertidal diversity and species interactions in central California. J Exp Mar Biol Ecol 393:90-99

Jannasch HW, Coletti LJ, Johnson KS, Fitzwater SE, Needoboa JA, Plant JN (2008) The Land/Ocean Biogeochemical Observatory: a robust networked mooring system for continuously monitoring complex biogeochemical cycles in estuaries. Limnol Oceanogr Methods: 263-276

Kanwisher JW (1966) Photosynthesis and respiration in some seaweeds. In: Barnes H (ed) Some contemporary studies in marine sciences. George Allen \& Unwin, London, p 407-420

Karlsson OM, Jonsson PO, Lindgren D, Malmaeus JM, Stehn A (2010) Indications of recovery from hypoxia in the inner Stockholm Archipelago. Ambio 39:486-495 Medline

Kemp WM, Boynton W, Adolf J, Boesch D and others (2005) Eutrophication of Chesapeake Bay: historical trends and ecological interactions. Mar Ecol Prog Ser 303:1-29

Largier JL, Hollibaugh JT, Smith SV (1997) Seasonally hypersaline estuaries in Mediterranean-climate regions. Estuar Coast Shelf Sci 45:789-797

Lüning K (1990). Seaweeds: their environment, biogeography, and ecophysiology. John Wiley \& Sons, New York, NY

> Martinetto P, Daleo P, Escapa M, Alberti J and others (2010) High abundance and diversity of consumers associated with eutrophic areas in a semi-desert macrotidal coastal ecosystem in Patagonia, Argentina. Estuar Coast Shelf Sci 88:357-364

> McGlathery KJ, Sundback K, Anderson IC (2007) Eutrophication in shallow coastal bays and lagoons: the role of plants in the coastal filter. Mar Ecol Prog Ser 348:1-18

> Monbet Y (1992) Control of phytoplankton biomass in estuaries: a comparative analysis of microtidal and macrotidal estuaries. Estuaries 15:563-571

National Research Council (2000) Clean coastal waters: understanding and reducing the effects of nutrient pollution. National Academy Press, Washington, DC

Nixon SW (1995) Coastal marine eutrophication: a definition, social causes, and future concerns. Ophelia 41: 199-219

> Nixon SW, Ammerman JW, Atkinson LP, Berounsky VM and others (1996) The fate of nitrogen and phosphorus at the land-sea margin of the North Atlantic Ocean. Biogeochemistry 35:141-180

Rabalais NN, Turner RE, Justić D, Dortch Q, Wiseman WJ Jr, Sen Gupta BK (1996) Nutrient changes in the Mississippi River and system responses on the adjacent continental shelf. Estuaries Coasts 19:386-407

> Ritter AF, Wasson K, Lonhart SI, Preisler RK and others (2008) Ecological signatures of anthropogenically altered tidal exchange in estuarine ecosystems. Estuaries Coasts 31:554-571

Rosenberg R, Nilsson HC, Diaz RJ (2001) Response of benthic fauna and changing sediment redox profiles over a hypoxic gradient. Estuar Coast Shelf Sci 53:343-350

Sandén P, Håkansson B (1996) Long-term trends in Secchi depth in the Baltic Sea. Limnol Oceanogr 41:346-351

Sanzone S, McElroy A (1998) Ecological impacts and evaluation criteria for the use of structures in marsh management. EPA-SABEPEC-98-003, Environmental Protection Agency, Washington, DC

- Scavia D, Bricker SB (2006) Coastal eutrophication assessment in the United States. Biogeochemistry 79:187-208

Schlesinger WH (2009) On the fate of anthropogenic nitrogen. Proc Natl Acad Sci USA 106:203-208

Shumchenia EJ, King JW (2010) Evaluation of sediment profile imagery as a tool for assessing water quality in Greenwich Bay, Rhode Island, USA. Ecol Indic 10: 818-825

Smith VH, Schindler DW (2009) Eutrophication science: where do we go from here? Trends Ecol Evol 24:201-207 Uncles RJ, Stephens JA, Smith RE (2002) The dependence of 
estuarine turbidity on tidal intrusion length, tidal range and residence time. Cont Shelf Res 22:1835-1856

Underwood AJ (1997) Experiments in ecology: their logical design and interpretation using analysis of variance. Cambridge University Press, Cambridge

US EPA (Environmental Protection Agency) (2000) Ambient aquatic life water quality criteria for dissolved oxygen (saltwater): Cape Cod to Cape Hatteras. EPA Publication 822-R-00-012. US EPA, Washington, DC

> Valiela I, McClelland J, Hauxwell J, Behr PJ, Hersh D, Foreman K (1997) Macroalgal blooms in shallow estuaries: controls and ecophysiological and ecosystem consequences. Limnol Oceanogr 42:1105-1118

Vitousek PM, Aber JD, Howarth RW, Likens GE and others (1997) Human alteration of the global nitrogen cycle:

Editorial responsibility: William Kemp,

Cambridge, Maryland, USA sources and consequences. Ecol Appl 7:737-750

Vollenweider RA (1976) Advances in defining critical loading levels of phosphorus in lake eutrophication. Mem Ist Ital Idrobiol 33:53-83

- Williams PB, Orr MK (2002) Physical evolution of restored breached levee salt marshes in the San Francisco Bay estuary. Restor Ecol 10:527-542

Young GC, Potter IC, Hyndes GA, De Lestang S (1997 The ichthyofauna of an intermittently open estuary: implications of bar breaching and low salinities on faunal composition. Estuar Coast Shelf Sci 45:53-68

Zimmerman AR, Canuel EA (2000) A geochemical record of eutrophication and anoxia in Chesapeake Bay sediments: anthropogenic influence on organic matter composition. Mar Chem 69:117-137

Submitted: September 21, 2010; Accepted: July 12, 2011 Proofs received from author(s): October 11, 2011 